\title{
Wissenschaftspreis des Deutschen Bundestages
}

Auch im Jahr 2012 wird der Deutsche Bundestag einen Wissenschaftspreis verleihen. Er würdigt hervorragende wissenschaftliche Arbeiten der jüngsten Zeit, die zur Beschäftigung mit den Fragen des Parlamentarismus anregen und zu einem vertieften Verständnis parlamentarischer Praxis beitragen. Der Preis, vom Parlament 1989 aus Anlass seines 40-jährigen Bestehens begründet, wird seit 1997 im zweijährigen Turnus verliehen. Er ist mit 10.000 Euro dotiert.

Wissenschaftliche Studien können sowohl vom Autor selbst als auch durch Dritte vorgeschlagen werden. Die Werke müssen in dreifacher Ausfertigung und nach Abschluss der gegebenenfalls vorangegangenen akademischen Verfahren eingereicht werden. Der Bewerbung ist ein Lebenslauf beizufügen. Berücksichtigt werden nur bereits publizierte Arbeiten, die seit dem 1. Juli 2010 erschienen sind. Die Auswahl der Preisträger erfolgt durch eine Fachjury aus Wissenschaftlern unterschiedlicher Disziplinen.

Bewerber und Befürworter preiswürdiger Arbeiten werden gebeten, sich bis zum 1. Juli 2012 an folgende Adresse zu wenden:

Deutscher Bundestag

Fachbereich WD 1

Wissenschaftspreis

Platz der Republik 1

11011 Berlin
E-Mail: vorzimmer.wd1@bundestag.de

Telefon: (030) 227-37410

Fax: (030) 227-36464 